\title{
Breast Milk Cytokine and IgA Composition Differ in Estonian and Swedish Mothers-Relationship to Microbial Pressure and Infant Allergy
}

\author{
SARA TOMIČIĆ, GIT JOHANSSON, TIIA VOOR, BENGT BJÖRKSTÉN, MALIN FAGERÅS BÖTTCHER, \\ AND MARIA C. JENMALM
}

Divisions of Paediatrics [S.T., M.F.B., M.C.J.], Cell Biology [G.J.], and Inflammation Medicine [M.C.J.], Linköping University, SE-581 85 Linköping, Sweden; Children's Clinic of Tartu University Clinics [T.V.], Tartu University, 51014 Tartu, Estonia; Institute of

Environmental Health [B.B.], Karolinska Institutet, SE-171 77 Stockholm, Sweden

\begin{abstract}
The immune system of the neonate is influenced by maternal immunity during pregnancy and lactation. An altered microbial exposure, possibly underlying the increase of allergic diseases in affluent societies, may affect maternal breast milk immune composition. Secretory IgA (SIgA), IL-4, IL-10, IL-13, IFN- $\gamma$, TGF- $\beta 1$, and TGF- $\beta 2$ were analyzed with ELISA in colostrum and 1-mo mature milk from mothers from Estonia $(n=39)$ and Sweden $(n=$ 60 ), the two geographically adjacent countries with different living conditions and allergy incidence. The IL-10 and IFN- $\gamma$ levels were higher in colostrum from Estonian than Swedish mothers, whereas the opposite was true for TGF- $\beta 2$. In mature milk, higher SIgA and IFN- $\gamma$ levels but lower TGF- $\beta 1$ and TGF- $\beta 2$ levels were observed in Estonian than Swedish mothers. Interestingly, in Sweden but not Estonia, the TGF- $\beta 1$ and TGF- $\beta 2$ levels correlated inversely with environmental endotoxin concentrations, whereas positive correlations to microbial load were observed for IL-4, IL-10, and IFN- $\gamma$. High colostral IL-13 levels were associated with allergic sensitization during infancy in Sweden. In conclusion, Estonian mothers have lower breast milk levels of TGF- $\beta$, particularly TGF- $\beta 2$, but higher levels of SIgA, IL-10, and IFN- $\gamma$ than Swedish mothers, possibly because of differences in microbial load. (Pediatr Res 68: 330-334, 2010)
\end{abstract}

$\mathrm{M}^{\prime}$ ucosal surfaces are the main entry for most environmental antigens, e.g. infectious agents and allergens. An integrated mucosal immune network of lymphoid and nonlymphoid cells and effector molecules, such as secretory IgA (SIgA), cytokines, and chemokines, is needed for host protection against pathogens and tolerance to commensal bacteria and innocuous antigens (1). The neonatal period is critical in this respect, because the newborn baby is immediately exposed to numerous microorganisms and foreign proteins. The mucosal immune system is poorly developed at birth, however, with only traces of SIgA and SIgM in exocrine glands, not reaching adult levels until several years after birth (2). Thus, an adequate supply

Received February 16, 2010; accepted June 11, 2010.

Correspondence: Maria C. Jenmalm, Ph.D., Department of Clinical and Experimental Medicine/AIR pl 10, Faculty of Health Sciences, Linköping University, SE-581 85 Linköping, Sweden; e-mail: maria.jenmalm@liu.se

Supported by Grants from the Swedish Research Council, the National Heart and Lung Association, The Vårdal Foundation-for Health Care Sciences and Allergy Research, the National Swedish Association against Allergic Diseases, and the County Council of Östergötland. of breast milk is essential for an optimal mucosal barrier function during the first months of life (3).

Breast milk contains numerous immunologic components that compensate for the immature and inexperienced mucosal immune system of the infant (4), including immune cells, antibodies (especially IgA antibodies), pro- and antiinflammatory cytokines such as TNF, IL-10, and TGF- $\beta$ (5), and factors that may modify immune responses to bacteria, e.g. soluble CD14 (6). Through the integrated mucosal immune system, immune responses induced in the gut and airway mucosal-associated lymphoid tissue are reflected in other secretory tissues, e.g. the mammary gland (3). Thus, primed $\mathrm{B}$ - and $\mathrm{T}$ cells are directed from inductive mucosal sites to other glandular tissues through the expression of specific adhesion molecules or "homing receptors" (1). Consequently, the immunologic composition of breast milk may vary considerably in mothers from different environments (3). Other factors suggested to affect the composition of breast milk include maternal allergy $(5,7)$, infections (8), mastitis (9), stress (8), delivery by Caesarean section (8), and supplementation of fish oil (10) and probiotics (11) during pregnancy. The controversial results regarding the role of breast-feeding for prevention of allergy development have been suggested to be partly because of differences in breast milk composition (12). For instance, high levels of breast milk IgA $(13-15)$ and TGF- $\beta(16,17)$ have been suggested to affect the allergy development in the child, although this is still controversial $(15,18-20)$.

We have previously shown that the microbial load differs between Estonian and Swedish populations, both with regard to the commensal gut flora (21) and the environmental endotoxin levels (22). As environmental microbes are the major stimuli of the immune system, the immune composition of breast milk may differ between mothers living in regions with different microbial burden. An increased microbial load is associated with a reduced prevalence of atopic diseases $(22,23)$. Therefore, the aim of this study was to investigate the breast milk content of atopy-related cytokines, i.e. IL-4, IL-13, and IFN- $\gamma$, anti-inflammatory cytokines, i.e. IL-10, TGF- $\beta 1$, and TGF- $\beta 2$, and SIgA in Estonian and Swedish mothers in

Abbreviations: SIg, secretory immunoglobulin; SPT, skin prick test 
Table 1. Characteristics of the Estonian and Swedish mothers and children, followed up to 24 mo of age

\begin{tabular}{lcc}
\hline & Estonian & Swedish \\
\hline No. of mothers & 39 & 60 \\
Mothers with allergic history & $14(36 \%)$ & $29(48 \%)$ \\
No. of born babies & 39 & 60 \\
No. of babies dropping out of the study & 0 & 7 \\
Cumulative incidence of SPT + & $3 / 39(8 \%)$ & $13 / 53(25 \%)$ \\
Cumulative incidence of eczema & $3 / 39(8 \%)$ & $10 / 53(19 \%)$ \\
\hline
\end{tabular}

relation to environmental endotoxin levels and development of sensitization and eczema in the breast-fed infants.

\section{MATERIALS AND METHODS}

Subjects. Samples of colostrum were obtained as soon as milk production started, within the first $4 \mathrm{~d}$ after delivery, and mature milk samples were obtained 1 mo after delivery from 39 Estonian and 60 Swedish mothers. The mothers participated in a prospective study regarding allergy development in children in relation to lifestyle factors, as described in detail previously (24). The allergic history of the mothers was recorded by a research nurse during an initial interview. Fourteen $(36 \%)$ of the Estonian and $29(48 \%)$ of the Swedish mothers reported a history of allergic symptoms, i.e. allergic rhinoconjunctivitis, asthma, or eczema (Table 1). The high number of allergic mothers was because of the increased interest among these mothers to participate in studies focusing on allergy. Except for allergy, none of the mothers had any autoimmune or other chronic disease. All mothers delivered their babies at term, and the perinatal period was normal. None of the Estonian mothers and three of the Swedish mothers had delivered their babies by cesarean section. The mean duration of exclusive breast-feeding was $2.8 \mathrm{mo}$ (range, 0.3-6.3 mo) in the Estonian mothers and 3.9 mo (range, 0.3-7.0 mo) in the Swedish mothers. For partial breast-feeding, the mean duration was 7.3 mo (range, 1.0-24 mo) in the Estonian mothers and 9.4 mo (range, 2.0-24 mo) in the Swedish mothers. The milk samples were collected in sterile, plastic tubes, using a manual breast pump. The samples were immediately frozen and stored at $-20^{\circ} \mathrm{C}$ until analysis.

Skin prick tests (SPTs) were performed at all follow-ups in duplicate at the volar aspects of the forearms with fresh skimmed cow's milk and thawed egg white at 3, 6, 12, and $24 \mathrm{mo}$. At $12 \mathrm{mo}$, the children were tested with cat allergen extract and also with mite allergen extract (Dermatophagoides pteronyssinus) in Estonian children. At 24 mo, birch and timothy allergen extract was added to the panel, and in Estonian children cockroach (Blatella germanica) allergen was also added. All extracts were standardized allergen extracts from ALK (Soluprick, ALK, Hørsholm, Denmark), except the cockroach extract, which was from Bayer (Spokane, WA). Histamine hydrochloride, $10 \mathrm{mg} / \mathrm{mL}$, was used as positive control and glycerol as negative. The test was regarded as positive if the mean diameter of one of the wheals was at least $3 \mathrm{~mm}$. The cumulative incidence of positive SPT up to $24 \mathrm{mo}$ of age was $8 \%$ (3/39) among the Estonian infants and 25\% (13/53) among the Swedish infants. Seven of the Swedish infants did not complete the study protocol up to 24 mo of age, whereas all the Estonian infants did (Table 1).

The presence of $\operatorname{IgE}$ antibodies to egg white and $\beta$-lactoglobulin were determined in serum samples collected at all follow-ups up to $24 \mathrm{mo}$, and $\operatorname{IgE}$ antibodies to cat and birch allergens were analyzed at 12 and 24 mo by a commercial chemiluminescence method, according to the recommendations of the manufacturer (Magic Lite; ALK). The test was regarded as positive at $>1.43 \mathrm{SU} / \mathrm{mL}$. The Swedish children were regarded as sensitized if they had a positive SPT and/or detectable circulating allergen-specific IgE antibodies, and the cumulative incidence of sensitization up to 24 mo of age was $34 \%$ (18/53). This definition was not applicable in the Estonian children, because low levels of circulating IgE antibodies is commonly detected and are poorly related to allergy and SPT positivity in these children (24). Consequently, the three SPT positive Estonian children were defined as sensitized.

A clinical examination regarding development of eczema was done by a pediatric allergologist when the infants were 24 mo old. Eczema was defined as pruritic, chronic, or chronically relapsing noninfectious dermatitis with typical features and distribution, as described previously (24). The cumulative incidence of eczema up to 24 mo of age was 8\% (3/39) among the Estonian infants and 19\% (10/53) among the Swedish infants (Table 1).

Cytokine, SIgA, and endotoxin analysis. Before analysis, the breast milk fatty layer and cellular elements were removed as previously described (5). IL-4, IL-10, IL-13, IFN- $\gamma$, TGF- $\beta 1$, TGF- $\beta 2$, and SIgA were analyzed as previously described (5). The detection limits were $5.6 \mathrm{pg} / \mathrm{mL}$ for IL-4, 4.8 $\mathrm{pg} / \mathrm{mL}$ for IL-10, $3.2 \mathrm{pg} / \mathrm{mL}$ for IL-13, $15.6 \mathrm{pg} / \mathrm{mL}$ for IFN- $\gamma, 62 \mathrm{pg} / \mathrm{mL}$ for TGF- $\beta 1$ and TGF- $\beta 2$ and $30 \mu \mathrm{g} / \mathrm{mL}$ for SIgA.

Dust samples were collected from a carpet in each household with a dust collector device, containing a $6-\mu \mathrm{m}$ pore size filter connected to a vacuum cleaner (22). Two square meters of the carpet was vacuum cleaned for $4 \mathrm{~min}$. The filters were stored in sterile plastic bags at $-20^{\circ} \mathrm{C}$ until analysis. The endotoxin concentration was determined by a chromogenic Limulus assay (QCL-1000, Bio Whittaker, Walkersville, ND) as described earlier (22). The lowest detection limit was $0.50 \mathrm{EU} / \mathrm{mg}$ dust.

Statistical analysis. The Mann Whitney $U$ test was used for unpaired analyses and Spearman's rank-order correlation coefficient test for correlation analyses. The $\chi^{2}$ test was used for categorical variables, and the Fisher's exact test was used when the expected frequency for any cell was $<5$. Differences combined with $p<0.05$ were considered statistically significant. The calculations were performed with the statistical packages StatView version 5.9 for PC (SAS Institute Inc, Cary, NC).

Ethical aspects. The study was approved by the Ethics Review Committee on Human Research of the University of Tartu and the Human Research Ethics Committee at the Faculty of Health Sciences, Linköping University. The parents of all children gave their written informed consent.

\section{RESULTS}

The TGF- $\beta 2$ levels were lower in colostrum and mature milk from Estonian than Swedish mothers (Fig. 1), whereas TGF- $\beta 1$ levels were lower only in mature milk (Fig. 1). In contrast, the SIgA levels were higher in Estonian than Swed-

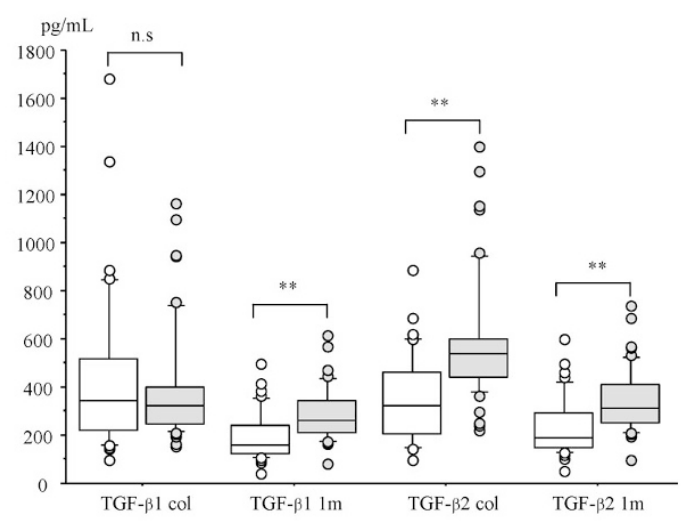

Figure 1. Lower breast milk levels of TGF- $\beta$, particularly TGF- $\beta 2$, in Estonian than Swedish mothers. Colostral and 1-mo mature milk TGF- $\beta 1$ and TGF- $\beta 2$ levels (pg/mL) in Estonian (white) and Swedish (gray) mothers. The 10th, 25th, 50th, 75th, and 90th percentiles and outliers are indicated. $* * p<0.0001$.

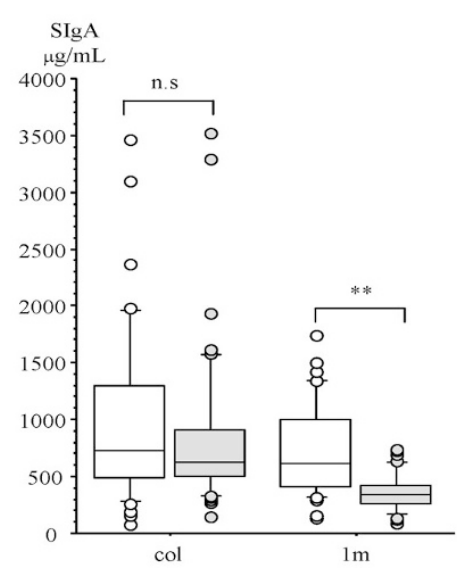

Figure 2. Higher levels of secretory $\operatorname{IgA}$ in mature milk from Estonian than Swedish mothers. Colostral and 1-mo mature milk secretory IgA levels $(\mu \mathrm{g} / \mathrm{mL})$ in Estonian (white) and Swedish (gray) mothers. The 10th, 25th, 50th, 75th, and 90th percentiles and outliers are indicated. $* * p<0.0001$. 
Table 2. Number (n) and percentage (\%) of colostrum and mature milk samples from Estonian and Swedish mothers with detectable levels

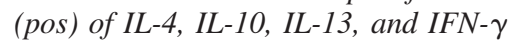

\begin{tabular}{|c|c|c|c|c|c|c|}
\hline & \multicolumn{3}{|c|}{ Colostrum } & \multicolumn{3}{|c|}{ Mature milk } \\
\hline & Estonian, $n$ pos $(\%)$ & Swedish, $n$ pos $(\%)$ & $p$ & Estonian, $n$ pos $(\%)$ & Swedish, $n$ pos $(\%)$ & $p$ \\
\hline IL-4 & $4 / 32(12 \%)$ & $18 / 60(30 \%)$ & 0.08 & $9 / 37(24 \%)$ & $11 / 49(22 \%)$ & $\mathrm{ns}$ \\
\hline IL-10 & $14 / 39(36 \%)$ & $6 / 60(10 \%)$ & 0.004 & $4 / 39(10 \%)$ & $3 / 48(6 \%)$ & $\mathrm{ns}$ \\
\hline IL-13 & $8 / 23(35 \%)$ & $21 / 59(36 \%)$ & ns & $11 / 32(34 \%)$ & $12 / 47(26 \%)$ & $\mathrm{ns}$ \\
\hline IFN- $\gamma$ & $9 / 38(24 \%)$ & $4 / 60(7 \%)$ & 0.03 & $6 / 38(16 \%)$ & $1 / 49(2 \%)$ & 0.04 \\
\hline
\end{tabular}

Pos, positive.

Statistically significant differences are marked in bold.

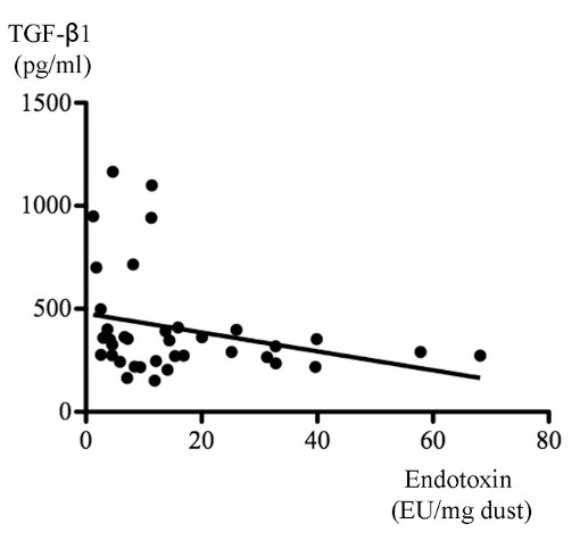

Figure 3. Inverse correlation between carpet dust endotoxin levels and colostral TGF- $\beta 1$ levels in Swedish mothers. Colostral TGF- $\beta 1$ levels (pg/ $\mathrm{mL}$ ) in relation to carpet dust endotoxin levels (EU/mg dust), rho $=-0.34$, $p=0.04$.

ish mothers (Fig. 2). Because the frequency of samples with detectable levels of IL-4, IL-10, IL-13, and IFN- $\gamma$ was $<35 \%$, the number of samples with detectable levels of these cytokines, rather than the concentrations, is reported (Table 2). IL-10 and IFN- $\gamma$ were more often detected in colostrum from Estonian than Swedish mothers, whereas the opposite tended to be true for IL-4. Furthermore, IL-4 was detected more often in allergic than nonallergic mothers in Sweden (44\% versus $16 \%, p=0.02)$, but not in Estonian mothers (14\% versus $11 \%$ ).

The endotoxin levels in carpet dust were higher in Estonian (median, 19.4; range, 0.5-97.0 EU/mg dust) than Swedish dust samples (median, 11.7; range, 1.3-68.2 EU/mg dust; $p=0.007$ ).

In the Swedish mothers, TGF- $\beta 1$ ( $r h o=-0.34, p=0.04$; Fig. 3) and TGF- $\beta 2$ (rho $=-0.30, p=0.07$ ) in colostrum correlated inversely with the endotoxin levels. In contrast, there were positive correlations among colostral IL-4, IL-10, and IFN- $\gamma$ levels and house dust endotoxin levels in Sweden (rho $=0.34-0.35, p=0.03$ ). No significant correlations were observed between breast milk cytokine levels and house dust endotoxin levels in Estonia.

High levels of IL-13 in breast milk were associated with early sensitization in Swedish breast-fed infants. This could not be evaluated in the Estonian infants, as only three of them were sensitized. All three Swedish infants who were sensitized at $3 \mathrm{mo}$ had received colostrum with detectable levels of IL-13, whereas the corresponding figure for nonsensitized infants was $30 \%$ ( 7 of $23, p=0.046$ ). For the infants who were sensitized at $6 \mathrm{mo}, 67 \%$ (4 of 6) had received colostrum with detectable IL-13, compared with $15 \%$ of the nonsensi- tized infants ( 4 of 27, $p=0.02$ ). High colostral TGF- $\beta 2$ levels also tended to be associated with sensitization in Sweden, especially during later infancy (median, 486; range, 240-1400 $\mathrm{pg} / \mathrm{mL}$ in nonsensitized versus median 586; range, 365-1156 $\mathrm{pg} / \mathrm{mL}$ in sensitized children; $p=0.11$ ). The IL-13 and TGF- $\beta 2$ levels were not significantly related to atopic dermatitis development. None of the other analyzed breast milk parameters were associated with sensitization or with atopic eczema (data not shown). However, it is worth noticing that $50 \%$ of the infants who were sensitized within the first 6 mo of life and then lost their SPT reactivity had received breast milk with detectable levels of IL-10 compared with none of the infants with sustained sensitization $(p=0.04)$.

\section{DISCUSSION}

The immune composition differs in breast milk from mothers of two geographically adjacent populations, with marked differences in lifestyle, environment, and allergy prevalence. Thus, Estonian mothers had lower levels of TGF- $\beta$, particularly TGF- $\beta 2$, but higher levels of SIgA, IL-10, and IFN- $\gamma$ in their breast milk than Swedish mothers. The low levels of the anti-inflammatory and IgA-inducing cytokine TGF- $\beta$ in breast milk from mothers of a country with high microbial pressure and low prevalence of allergic disease may seem counterintuitive. This finding is in accordance with our recent observations that probiotic Lactobacillus reuteri supplementation reduces TGF- $\beta 2$ levels in breast milk, however (11), and possibly related to improved epithelial barrier function. A certain microbial pressure may be mandatory for preservation of an intact mucosal barrier function (25). In response to epithelial damage, TGF- $\beta$ drives tissue remodelling, inducing fibrosis and airway smooth muscle proliferation in asthma $(26,27)$. Thus, it is tempting to speculate that TGF- $\beta 2$ levels in breast milk may increase after mammary epithelial damage. In addition, IL-13 induces epithelial cells to produce TGF- $\beta$, particularly TGF- $\beta 2(28,29)$, a process inhibited by IFN- $\gamma$ (30). In contrast to epithelial cells where TGF- $\beta 2$ dominates, immune cells including $\mathrm{T}$ regulatory cells preferentially express the TGF- $\beta 1$ isoform $(31,32)$. Adding to the complexity in TGF- $\beta$-mediated effects, this pleiotropic cytokine may, in concert with proinflammatory mediators such as IL-6 or the Th2 cytokine IL-4, induce potentially airway inflammation aggravating T helper cells producing IL-17 (32-34) and IL-9 $(27,35,36)$, respectively. These proinflammatory properties may be related to our findings of low TGF- $\beta$ levels in Estonian, compared with Swedish, mothers. 
The integrated mucosal immune system entails that immune responses induced in the gut or airways can be reflected in the mammary gland $(3,37)$. Because microbes and their products are major factors regulating mucosal immunity, it is tempting to speculate that the microbial environment would influence the breast milk composition. Supporting this hypothesis, the house dust endotoxin levels correlated inversely to the colostral levels of TGF- $\beta$, but positively to IL-4, IL-10, and IFN- $\gamma$ in colostrum of Swedish mothers. Taken together, these findings indicate that a high external microbial load is associated with low TGF- $\beta$, but high IL-4, IL-10, and IFN- $\gamma$ responses at the mammary epithelium. The lack of direct association between endotoxin and breast milk cytokines in the Estonian mothers is possibly because of the generally high endotoxin levels in Estonia (22) already providing a maximal effect.

Many bacteria and microbial-derived products induce the production of IFN- $\gamma$ and IL-10, and occasionally also IL-4, from $\mathrm{T}$ cells and antigen-presenting cells located beneath the mucosal epithelium $(38,39)$. These cells will then specifically migrate to other mucosal sites, and their cytokine production is mirrored in secretions such as the breast milk. This may explain the higher levels of IL-4, IL-10, and IFN- $\gamma$ in individuals living in an environment with high microbial load. We have previously observed higher colostral IL-10 levels in mothers treated with Lactobacillus reuteri when compared with placebo (11). Most IgA antibodies in mucosal secretions are directed against microbial antigens (3). Thus, the higher SIgA levels in mature milk of Estonian, compared with Swedish, mothers are possibly because of the more divergent microbial environment of the former population, although no correlation between SIgA levels and endotoxin was found.

Speculatively, the association between high colostral IL-13 levels and early sensitization may be related to the IgEinducing capacity of IL-13, which may dominate the effects of IL-4 when this more tightly regulated cytokine is absent or present at low levels, e.g. during the initiation of allergic responses (40). Furthermore, IL-13 induces epithelial cells to produce TGF- $\beta$, particularly TGF- $\beta 2(28,29)$. We observed a tendency toward increased colostral TGF- $\beta 2$ levels among sensitized infants, in accordance with our findings in the Lactobacillus reuteri-treated cohort (11). Possibly, the relation between breast milk TGF- $\beta 2$ levels and childhood sensitization is explained by epithelial barrier function. Thus, high TGF- $\beta 2$ levels in milk mirror increased epithelial permeability, as determined by the milk $\mathrm{Na} / \mathrm{K}$ ratio (11). An increased epithelial permeability has previously been associated with development of sensitization and allergic symptoms up to 18 mo of age also in another independent cohort (41). In partial contrast to our findings, infants with postweaning onset allergic disease received colostrum with higher TGF- $\beta 2$ levels than infants with preweaning onset of disease (16). However, this observation is still controversial $(15,18,20)$. That children with transient when compared with persistent sensitization during infancy more often received colostrum with detectable IL-10 may be related to the IgE inhibitory effects of this cytokine (26).

In conclusion, Estonian mothers have lower levels of TGF- $\beta$, particularly TGF- $\beta 2$, but higher levels of SIgA, IL-
10 , and IFN- $\gamma$ in their breast milk than Swedish mothers, possibly because of the differences in microbial load. High IL-13 levels may be associated with increased risk of sensitization during infancy.

Acknowledgments. We thank the research nurse, Lena Lindell, for her enthusiastic work in guiding the families through the study and all sampling procedures, Ammi Fornander for excellent technical assistance, and Karel Duchén for clinical evaluation.

\section{REFERENCES}

1. Cerutti A, Rescigno M 2008 The biology of intestinal immunoglobulin A responses Immunity 28:740-750

2. Cripps AW, Gleeson M, Clancy RL 1991 Ontogeny of the mucosal immune response in children. Adv Exp Med Biol 310:87-92

3. Brandtzaeg P 2003 Mucosal immunity: integration between mother and the breastfed infant. Vaccine 21:3382-3388

4. Field CJ 2005 The immunological components of human milk and their effect on immune development in infants. J Nutr 135:1-4

5. Böttcher MF, Jenmalm MC, Garofalo RP, Björkstén B 2000 Cytokines in breast milk from allergic and nonallergic mothers. Pediatr Res 47:157-162

6. Labéta MO, Vidal K, Nores JE, Arias M, Vita N, Morgan BP, Guillemot JC, Loyaux D, Ferrara P, Schmid D, Affolter M, Borysiewicz LK, Donnet-Hughes A, Schiffrin EJ 2000 Innate recognition of bacteria in human milk is mediated by a milk-derived highly expressed pattern recognition receptor, soluble CD14. J Exp Med 191:18071812

7. Böttcher MF, Jenmalm MC, Björkstén B, Garofalo RP 2000 Chemoattractant factors in breast milk from allergic and nonallergic mothers. Pediatr Res 47:592-597

8. Groer M, Davis M, Steele K 2004 Associations between human milk SIgA and maternal immune, infectious, endocrine, and stress variables. J Hum Lact 20:153158

9. Filteau SM, Rice AL, Ball JJ, Chakraborty J, Stoltzfus R, de Francisco A, Willumsen JF 1999 Breast milk immune factors in Bangladeshi women supplemented postpartum with retinol or beta-carotene. Am J Clin Nutr 69:953-958

10. Dunstan JA, Roper J, Mitoulas L, Hartmann PE, Simmer K, Prescott SL 2004 The effect of supplementation with fish oil during pregnancy on breast milk immunoglobulin A, soluble CD14, cytokine levels and fatty acid composition. Clin Exp Allergy 34:1237-1242

11. Böttcher MF, Abrahamsson TR, Fredriksson M, Jakobsson T, Björkstén B 2008 Low breast milk TGF-beta2 is induced by Lactobacillus reuteri supplementation and associates with reduced risk of sensitization during infancy. Pediatr Allergy Immunol 19:497-504

12. Friedman NJ, Zeiger RS 2005 The role of breast-feeding in the development of allergies and asthma. J Allergy Clin Immunol 115:1238-1248

13. Järvinen KM, Laine ST, Järvenpää AL, Suomalainen HK 2000 Does low IgA in human milk predispose the infant to development of cow's milk allergy? Pediatr Res 48:457-462

14. Machtinger S, Moss R 1986 Cow's milk allergy in breast-fed infants: the role of allergen and maternal secretory IgA antibody. J Allergy Clin Immunol 77:341-347

15. Savilahti E, Siltanen M, Kajosaari M, Vaarala O, Saarinen KM 2005 IgA antibodies, TGF-beta1 and -beta2, and soluble CD14 in the colostrum and development of atopy by age 4 . Pediatr Res 58:1300-1305

16. Kalliomäki M, Ouwehand A, Arvilommi H, Kero P, Isolauri E 1999 Transforming growth factor-beta in breast milk: a potential regulator of atopic disease at an early age. J Allergy Clin Immunol 104:1251-1257

17. Saarinen KM, Vaarala O, Klemetti P, Savilahti E 1999 Transforming growth factor-beta1 in mothers' colostrum and immune responses to cows' milk proteins in infants with cows' milk allergy. J Allergy Clin Immunol 104:1093-1098

18. Böttcher MF, Jenmalm MC, Björkstén B 2003 Cytokine, chemokine and secretory IgA levels in human milk in relation to atopic disease and IgA production in infants. Pediatr Allergy Immunol 14:35-41

19. Snijders BE, Damoiseaux JG, Penders J, Kummeling I, Stelma FF, van Ree R, van den Brandt PA, Thijs C 2006 Cytokines and soluble CD14 in breast milk in relation with atopic manifestations in mother and infant (KOALA Study). Clin Exp Allergy 36:1609-1615

20. Oddy WH, Rosales F 2010 A systematic review of the importance of milk TGF-beta on immunological outcomes in the infant and young child. Pediatr Allergy Immunol 21:47-59

21. Björkstén B, Naaber P, Sepp E, Mikelsaar M 1999 The intestinal microflora in allergic Estonian and Swedish 2-year-old children. Clin Exp Allergy 29:342-346

22. Böttcher MF, Björkstén B, Gustafson S, Voor T, Jenmalm MC 2003 Endotoxin levels in Estonian and Swedish house dust and atopy in infancy. Clin Exp Allergy 33:295-300

23. Guarner F, Bourdet-Sicard R, Brandtzaeg P, Gill HS, McGuirk P, van Eden W, Versalovic J, Weinstock JV, Rook GA 2006 Mechanisms of disease: the hygiene hypothesis revisited. Nat Clin Pract Gastroenterol Hepatol 3:275-284

24. Voor T, Julge K, Böttcher MF, Jenmalm MC, Duchen K, Björkstén B 2005 Atopic sensitization and atopic dermatitis in Estonian and Swedish infants. Clin Exp Allergy $35: 153-159$ 
25. Cario E, Gerken G, Podolsky DK 2004 Toll-like receptor 2 enhances ZO-1associated intestinal epithelial barrier integrity via protein kinase C. Gastroenterology 127:224-238

26. Lloyd CM, Hawrylowicz CM 2009 Regulatory T cells in asthma. Immunity 31:438449

27. Qian BF, Wahl SM 2009 TGF-beta can leave you breathless. Curr Opin Pharmacol 9:454-461

28. Richter A, Puddicombe SM, Lordan JL, Bucchieri F, Wilson SJ, Djukanovic R, Dent G, Holgate ST, Davies DE 2001 The contribution of interleukin (IL)-4 and IL-13 to the epithelial-mesenchymal trophic unit in asthma. Am J Respir Cell Mol Biol 25:385-391

29. Chu HW, Balzar S, Seedorf GJ, Westcott JY, Trudeau JB, Silkoff P, Wenzel SE 2004 Transforming growth factor-beta2 induces bronchial epithelial mucin expression in asthma. Am J Pathol 165:1097-1106

30. Wen FQ, Kohyama T, Liu X, Zhu YK, Wang H, Kim HJ, Kobayashi T, Abe S, Spurzem JR, Rennard SI 2002 Interleukin-4- and interleukin-13-enhanced transforming growth factor-beta2 production in cultured human bronchial epithelial cells is attenuated by interferon-gamma. Am J Respir Cell Mol Biol 26:484-490

31. Marie JC, Letterio JJ, Gavin M, Rudensky AY 2005 TGF-beta1 maintains suppressor function and Foxp3 expression in CD4+CD25+ regulatory T cells. J Exp Med 201:1061-1067

32. Li MO, Flavell RA 2008 TGF-beta: a master of all T cell trades. Cell 134:392-404

33. Mangan PR, Harrington LE, O'Quinn DB, Helms WS, Bullard DC, Elson CO, Hatton RD, Wahl SM, Schoeb TR, Weaver CT 2006 Transforming growth factorbeta induces development of the Th17 lineage. Nature 441:231-234

34. Volpe E, Servant N, Zollinger R, Bogiatzi SI, Hupe P, Barillot E, Soumelis V 2008 A critical function for transforming growth factor-beta, interleukin 23 and proin- flammatory cytokines in driving and modulating human Th17 responses. Nat Immunol 9:650-657

35. Dardalhon V, Awasthi A, Kwon H, Galileos G, Gao W, Sobel RA, Mitsdoerffer M, Strom TB, Elyaman W, Ho IC, Khoury S, Oukka M, Kuchroo VK 2008 IL-4 inhibits TGF-beta-induced Foxp3 + T cells and, together with TGF-beta, generates IL-9+ IL-10+ Foxp3(-) effector T cells. Nat Immunol 9:1347-1355

36. Veldhoen M, Uyttenhove C, van Snick J, Helmby H, Westendorf A, Buer J, Martin B, Wilhelm C, Stockinger B 2008 Transforming growth factor-beta 'reprograms' the differentiation of T helper 2 cells and promotes an interleukin 9-producing subset. Nat Immunol 9:1341-1346

37. Ahlstedt S, Carlsson B, Fällströom SP, Hanson LÅ, Holmgren J, Lidin-Janson G, Lindblad BS, Jodal U, Kaijser B, Solh-Åkerlund A, Wadsworth C 1977 Antibodie in human serum and milk induced by enterobacteria and food proteins. In: Porter $\mathrm{R}$, Knight J (eds) Ciba Foundation Symposium 46-Immunology of the Gut. John Wiley and Sons, Inc. Hoboken, NJ, pp 115-134

38. Hall JA, Bouladoux N, Sun CM, Wohlfert EA, Blank RB, Zhu Q, Grigg ME, Berzofsky JA, Belkaid Y 2008 Commensal DNA limits regulatory T cell conversion and is a natural adjuvant of intestinal immune responses. Immunity 29:637-649

39. Round JL, Mazmanian SK 2009 The gut microbiota shapes intestinal immune responses during health and disease. Nat Rev Immunol 9:313-323

40. Punnonen J, Yssel H, de Vries JE 1997 The relative contribution of IL-4 and IL-13 to human IgE synthesis induced by activated CD4+ or CD8 + T cells. J Allergy Clin Immunol 100:792-801

41. Benn CS, Böttcher MF, Pedersen BV, Filteau SM, Duchén K 2004 Mammary epithelial paracellular permeability in atopic and non-atopic mothers versus childhood atopy. Pediatr Allergy Immunol 15:123-126 